\title{
EDUCAÇÃO ESTATÍSTICA NA EDUCAÇÃO DE JOVENS E ADULTOS
}

\section{STATISTICAL EDUCATION IN YOUTH AND ADULT EDUCATION}

\author{
Márcio José Silva ${ }^{1}$ \\ Reinaldo Feio Lima ${ }^{2}$ \\ Pedro Franco de $\mathrm{Sá}^{3}$
}

\begin{abstract}
Resumo: Esta pesquisa tratou de um ensaio teórico a cerca da educação estatística na Educação de Jovens e Adultos (EJA), cujo objetivo foi detacar a necessidade de se trabalhar com os conteúdos de Estatística na EJA na perspectiva da Educação Estatística, quando o foco central está na aprendizagem a partir da realidade de vida do aluno. A metodologia usada teve como alicerse teórico, os estudos Severino (2007), sobre ensaio teórico. Os resultados encontrados apontaram indicios de que a Educação Estatística na EJA é relevante para aprendizagem do aluno, pois contribui para sua formaçaõ enquanto cidadão estatisticamente crítico e reflexivos, com habilidades de avaliar as informações estatísticas presentes no seu cotidiano. Esperamos, portanto, que a partir desse breve ensaio teórico, futuros estudos possam abordar com maior profundidade o tratamento de informação na EJA a partir do dia a dia do aluno através de atividades investigativas em sala de aula e do uso das Tecnologias de Informação e Comunicação
\end{abstract}

Palavras-chave: Educação Estatística; Ensino de Estatística; EJA.

\begin{abstract}
This research was a theoretical essay about statistical education in Youth and Adult Education (EJA), whose objective was to highlight the need to work with the contents of Statistics in EJA from the perspective of Statistical Education, when the central focus is in learning from the student's reality of life. The methodology used had as theoretical foundation, the studies Severino (2007), on theoretical essay. The results found indicated that Statistical Education in EJA is relevant to student learning, as it contributes to their formation as a statistically critical and reflective citizen, with the ability to evaluate the statistical information present in their daily lives. We hope, therefore, that from this brief theoretical essay, future studies will be able to address in more depth the treatment of information in EJA from the student's daily life through investigative activities in the classroom and the use of Information and Communication Technologies.
\end{abstract}

Keywords: Statistical Education; Teaching Statistics; EJA.

\section{Apresentação}

Este artigo se constitui em um ensaio teórico de questões sobre Educação Estatística (EE) na Educação de Jovens e Adultos (EJA) no que tange, respectivamente, a uma breve reflexão sobre a EJA, a importancia da Educação Estatistica na EJA e,

\footnotetext{
${ }^{1}$ Mestre em Educação pela Universidade do Estado do Pará (UEPA). Docente da Universidade do Estado do Pará (UEPA), Moju, Pará, Brasil. E-mail: cmarcio44@ gmail.com

2 Doutorando em Educação pela Universidade Federal da Bahia (UFBA). Professor Assistente da área temática Educação Matemática da Universidade Federal do Sul e Sudeste do Pará (UNIFESSPA), Marabá, Pará, Brasil. E-mail: reinaldo.lima@unifesspa.edu.br

3 Doutor em Educação pela Universidade Federal do Rio Grande do Norte (UFRN). Docente do Centro de Ciências Sociais e Educação (CCSE), da Universidade do Estado do Pará (UEPA), Belém, Pará, Brasil.E-mail: psa@digi.com.br
} 


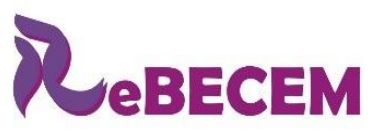

DOI: http://dx.doi.org/10.33238/ReBECEM.2019.v.3.n.2.22619

apontamentos sobre algumas interfaces na Educação de Jovens e Adultos. Neste contexto, emerge a necessidade de buscar estudos que fundamentem as implicações da Educação Estatística no cenário da EJA. Além disso, esperamos esboçar algumas reflexões teóricas que possa dar base para o professor e para o pesquisador desempacotar o ensino e aprendizagem desta área de forma mais eficaz em sala de aula.

Compreendemos que a área de pesquisa da Educação Estatística, que de acordo com Silva, Curi e Schimiguel (2017), procura:

\begin{abstract}
Aliar o desenvolvimento de competências como literácia, o raciocínio e o pensamento esatatatpistico ao uso de dados contextualizados, objetivando evidenciar a interpretação dos dados e resultados das analises em contraponto a simples manipulação de fórmulas por meio de cálculos complexos (SILVA; CURI; SCHIMIGUEL, 2017, p. 670).
\end{abstract}

Além disso, esta área tem estudado problemas relacionados ao ensino e aprendizagem referentes a análise combinatória, probabilidade e estatística nos diferentes níveis de ensino, considerando as interfaces existentes nos raciocínios necessários ao estudo dessas temáticas, o que envolve os aspectos cognitivos e afetivos do ensino e de aprendizagem, além da epistemologia e o desenvolvimento de métodos e materiais de ensino (CAZORLA; KATAOKA; SILVA, 2010; LOPES, 2010).

A partir deste entendimento acerca da EE, justificamos o olhar para a Educação de Jovens e Adultos, pois o ensino de Estatística está incluído, no componente curricular de Matemática, nos documentos oficiais que regem a Educação Básica brasileira, por exemplo, os Parâmetros Curriculares Nacionais (PCN), que introduzem a Estatística desde os Anos Iniciais do Ensino Fundamental (BRASIL, 1997).

Com isso, se torna relevante dialogar com as bases teóricas da EE na perspectiva da EJA, para que este possa ter elementos para subsidiar o ensino e a aprendizagem de conceitos Estatísticos, Combinatótio e Probabilístico na Educação de Jovens e Adultos (LOPES, 2013; MAGALHÃES, 2015).

Apesar das pesquisas na área da Educação Estatística estarem aumentando no âmbito nacional e internacional, haja vista a criação e a trajetória crescente da produção científica do GT12 (Grupo de Trabalho sobre Ensino de Probabilidade e Estatística) da Sociedade Brasileira de Educação Matemática (SBEM), que reúne pesquisadores preocupados com essa temática.

Esse fato é constatado nos estudos realizados por Silva, Curi e Schimiguel (2017), os quais trataram em suas pesquisas sobre um cenário refefente a Pesquisa em Educação Estatística no Boletim de Educação Matemática - BOLEMA, de 2006 até 


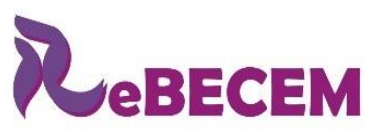

Revista Brasileira de Educação em

Ciências e Educação Matemática

ISSN 2594-9179

DOI: http://dx.doi.org/10.33238/ReBECEM.2019.v.3.n.2.22619

2015. Além disso, temos os estudos de Guimarães et al., (2009), que abordam o Estado da Arte das pesquisas sobre Educação Estatística na Educação Infantil e nos anos iniciais do Ensino Fundamental. Temos também, corroborando com esta pesquisa, os estudos de Bianchini e Nehring (2012), que abordaram sobre algumas produções acadêmicas nos anos de 2010 e 2011 a respeito do Ensino de Estatística e a formação de professores.

Segundo Cazorla, Kataoka e Silva (2010), dois eventos foram preponderantes para a consolidação da história do movimento da Educação Estatística no Brasil. O primeiro foi a Conferência Internacional "Experiências e Expectativas do Ensino de Estatística: desafios para o Século XXI”, sediada na Universidade Federal de Santa Catarina (UFSC), em Florianópolis/SC. O segundo foi a visita da pesquisadora espanhola Carmem Batanero, ao Programa da Universidade Estadual de Campinas (UNICAMP), a convite do Grupo de Pesquisa "Prática Pedagógica em Matemática" (PRAPEM), ambos ocorream no ano de 1999.

Como se pode notar, as pesquisas citadas acima nos chamam a atenção para a necessidade de se trabalhar na perspectiva da Educação Estatística em sala de aula da EJA. Dessa forma, nossa intenção é evidenciar a necessidade de se trabalhar os conteúdos de Estatística na EJA na perspectiva da Educação Estatística, quando o foco central está na aprendizagem.

Sendo assim, não pretendemos conduzir por uma revisão de literatura sistemática. Nem procuramos trazer à tona o que supostamente está oculto nos textos que fizeram parte de nossas leituras. Não garimpamos pelas intenções dos autores que discutem o ensino da Educação Estatística. Para este estudo, reivindimos liberdade interpretativa. Inspirado na noção de ensaio teórico, cujas bases alicerçam um estudo bem aprofundado, formal, discursivo e concludente que segundo Severino (2007), essa é uma modalidade que consiste em uma maior liberdade no sentido de defender uma idéia por meio de uma reflexão lógica em alto nível de interpretação pessoal, pois se realizou "a partir do registro disponível, decorrente de pesquisas anteriores" (SEVERINO, 2007, p. 122), especificamente, nos artigos sobre Educação Estatística que estão disponíveis online. A abordagem foi qualitativa na medida em que além de identificar os fundamentos da EE, buscou-se evidenciar os argumentos que as sustentam.

Logo, o presente estudo, portanto, se constitui numa modalidade de ensaio teórico, isto é, "um estudo bem desenvolvido, formal, discursivo e concludente, 


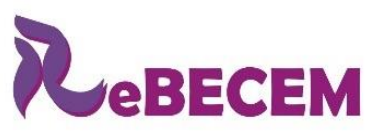

DOI: http://dx.doi.org/10.33238/ReBECEM.2019.v.3.n.2.22619

consistindo numa exposição lógica e reflexiva e numa argumentação rigorosa com alto nível de interpretação e julgamento pessoal" (SEVERINO, 1996, p. 120). Mas não se trata, frisamos de um trabalho teórico puro, já que estamos subsidiados pelos estudos apresentados na literatura nacional e internacional e em nossas próprias experiências de Educação Estatística em sala de aula. Apresentamos neste trabalho, de maneira sistematizada, o esboço de uma perspectiva de investigação para professores que ensinam Matemática.

Dessa forma, tivemos como ponto de partida, conforme mencionado antes, tecer as principais características da EJA. Em seguida, apresentar a fundamentação teórica da Educação Estatística e, por último, buscamos postar uma discussão de possibilidades de interface entre esses dois pontos no que concerne a possibilidade de desenvolvimento de aprendizagem, ou seja, da presença da Educação Estatistica na EJA. Para tanto, foram feitas, a seguir, algumas reflexões iniciais acerca da EJA. Portanto, consideramos este artigo como um estudo teórico, o qual tomou um conjunto de outros artigos para interlocução.

\section{Educação de Jovens e Adultos: uma reflexão inicial}

A Educação de Jovens e Adultos (EJA) é uma modalidade de ensino que é caracterizada como um meio para promover a escolarização para aquelas pessoas que nas mais diversas razões estiveram distantes dos bancos escolares em idade regular.

Nesse intento, Arroyo (2005) reforça a ideia de que o direito a educação de jovens e adultos deve ultrapassar uma mera oferta de uma segunda possibilidade de continuidade escolar, em que se torna necessário buscar um novo olhar para esta modalidade de ensino. Esclarecendo que:

O campo da EJA está se firmando de maneira muito intensa com sua
especificidade, com suas dificuldades próprias e também com suas
deficiências que precisam ser vencidas. Quem trabalha com Educação de
jovens e adultos não atende pessoas "desencantadas" com a educação, mas
sujeitos que chegam na escola carregando saberes, vivências, culturas,
valores, visões de mundo e de trabalho. Estão ali também como sujeitos da
construção desse espaço que tem suas características próprias e uma
identidade construída coletivamente entre educandos e educadores
(ARROYO, 2003, p. 7).

Partindo dessa concepção, somado as nossas experiencias na sala de aula da EJA, somos constantimente questionados a respeito de como trabalhar com esse público com características tão diferenciadas, e cabe à escola e, consequentemente, ao professor proporcionar aos estudantes, as compreensões a respeito da Estatística, da Probabilidade 


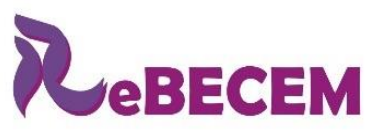

DOI: http://dx.doi.org/10.33238/ReBECEM.2019.v.3.n.2.22619

e da Combinatória, para que possam exercer sua cidadania de forma plena, tratando as informações que recebem adequadamente, refletindo e até mesmo questionando as verdades apresentadas (DIAS; SILVA; JUNIOR, 2017). Acerca disso, Fonseca (2002, p. 64), assevera que "é preciso, entretanto, avançar em alguns pontos cruciais como a discussão dos critérios de seleção dos conteúdos a serem contemplados, e principalmente, o tratamento que se deve conferir aos saberes populares".

Sobre isso, Fantinato (2006, p. 176) ressalta que:

A interação, portanto, entre esses conhecimentos construídos ao longo da vida, muitas vezes de maneira informal e os conhecimentos matemáticos escolares, passa a ser uma questão fundamental a ser elucidada, no sentido de vir a contribuir para as práticas pedagógicas em educação de jovens e adultos.

Ou seja, é preciso que se enfatize a utilização dos conhecimentos prévios dos estudantes como ponto de ligação com o conhecimento escolar o que pode contribuir, significativamente, para o entendimento de determinado conteúdo matemática, pois a utilização de conhecimentos de vida prática, referentes à sua vivência no trabalho e na comunidade da qual fazem parte, passam a ter um significado maior para os estudantes, pois estão vivenciando a aplicabilidade na vida diária. Assim, o cotidiano dos estudantes está impregnado dos saberes e fazeres próprios da sua realidade (D’AMBRÓSIO, 2002; CARRAHER; CARRAHER, 2006).

Cabe, portanto, ao professor ou pesquisador, buscar ultrapassar obstáculos, tanto no âmbito didático, quanto epstemológico, e definir um novo papel para educação escolar para pessoas jovens e adultos, por meio de um desenvolvimento curricular que esteja em consonancia com a realidade experienciada pelos alunos da EJA, a fim de que a educação escolar possa integralizar o currículo escolar com a vida laboral das vivencias pela maioria dos estudantes dessa modalidade de ensino. Desse modo, pesquisas voltadas para a vida laboral de feirantes, comerciantes, produtores de carvão, plantadores de dendê, borracheiros, vendedores de suco de frutas, bicheiros, indígenas, pintores, dentre outros, são objetos de investigação das potencialidades de práticas sociais como material pedagógico. Pois, na fase adulta estes individuos já dispõem de uma bagagem cultural que serve de ponte de ligação para aplicar esses conhecimentos já adquiridos e aprimorados por meio de atividades prática e utilitária que lhes são propostas pelo professor em sala, dando sentido atual e interpretando suas aplicações, pois as situações de ensino-aprendizagem em Matemática nos permitem momentos 


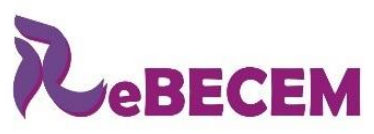

Revista Brasileira de Educação em

Ciências e Educação Matemática

ISSN 2594-9179

DOI: http://dx.doi.org/10.33238/ReBECEM.2019.v.3.n.2.22619

particularmente férteis de construção de significados realizados conscientemente pelos estudantes (FONSECA, 2005).

Dessa forma, torna-se necessário problematizar atividades de ensino de matemática, em especial no que tange a conteudos que envolvam o tratamento de informações, produzidas a partir da articulação entre os conhecimentos matemáticos enraizados nas atividades laborais dos estudantes da EJA e os conhecimentos matemáticos requisitados pela prática escolar. Nesse sentido, é primordial partir dos conceitos decorrentes de suas vivências, suas interações sociais e experiências pessoais: como detém conhecimentos amplos e diversificados, podem enriquecer a abordagem escolar, formulando questionamentos, confrontando possibilidades, propondo alternativas a serem consideradas (BRASIL, 2002).

Assim, se é de grande importância a problematização e contextualização, conforme versado antes, das interações de conteúdos curriculares, como forma de motivar o estudante no desenvolvimento e amadurecimento na construção do seu conhecimento. Dessa forma, a EJA possui uma especificidade própria, ou seja, apresentam características próprias o que diferencia das crianças, o que exige metodologias e material didático adequados ao processo de ensino e à aprendizagem do estudante adulto.

É importante, portanto, que o professor procure buscar desenvolver e/ou mobilizar na sala de aula competências e saberes, nesse caso, dos saberes referente ao cálculo da probabilidade como, por exemplo, o aluno saber calcular a probabilidade de um evento condicionado a um determindado espaço amastral, eventos independentes, evento impossivel e, saber a partir da organização de dados tabulados e gáficos sobre uma determinada pesquisa, interpretar, não só tabelas quanto gráficos estatísticos, por meio de elaboração de propostas didático-pedagógicas que os permita atender às especificidades dos educandos da EJA, ou seja, a esse respeito, Lopes (2010, p. 58), aponta como uma das causas da ausência dessa temática no trabalho com os estudantes a "falta de domínio teórico-metodológico do professor sobre os conceitos estatísticos e probabilísticos".

No que se refere à organização e planejamento de práticas pedagógicas envolvendo a Educação Estatística na EJA, Campos et al., (2011), salientam que é importante possibilitar aos alunos, em geral, a oportunidade de construir os próprios dados e "encontrar os resultados básicos ajuda-os a tomar as rédeas de seu próprio 
DOI: http://dx.doi.org/10.33238/ReBECEM.2019.v.3.n.2.22619

aprendizado, isto é, não apenas coletem os seus dados, mas, igualmente elaborem as variáveis que irão compor seus questionários” (CAMPOS et al., 2011, p. 25-26).

Além disso, Brasil (2002, p. 23) advoga que:

Os assuntos referentes a estatística, probabilidade e combinatória também precisam ser levados em conta pelos professores do Segundo Segmento da EJA, pois integram o rol de conhecimentos indispensáveis à alfabetização matemática, tão necessária para sobreviver no mundo atual, e podem ser articulados num grande tema denominado "tratamento da informação". Além disso, são ferramentas importantes para análise das chamadas questões sociais urgentes, a serem trabalhadas transversalmente. É importante oferecer aos alunos da EJA oportunidades para interpretar problemas, compreender enunciados, utilizar informações dadas, estabelecer relações, interpretar resultados à luz do problema colocado e enfrentar, com isso, situações novas e variadas (BRASIL, 2002, p. 74).

Nesse sentido, ainda de acordo com Brasil (2002, p. 84) nessa fase da vida escolar, "faz-se necessário uma metodologia de ensino que priorize a análise de situações da atividade de trabalho dos alunos extraindo dali noções, idéias e princípios dos conhecimentos matemáticos escolares".

Desse modo, é fundamental que o profeesor durante as atividades realizadas em sala leve em consideração as experiências práticas dos alunos e os acontecimentos reais sobre o meio social dele como economia, política, esporte o que nos atenta para a necessidade de se trabalhar a inserssão em acontecimentos reais para se poder fazer análise, provocar debates, questionamentos, coletar dados e organizá-los de maneira crítica. Assim, o ensino e a aprendizagem de Educação Estatística em EJA, devem envolver os três "atores" participantes no processo de ensino e aprendizagem, isto é, o aluno, o professor e o saber, sendo necessário o estabelecimento de "outros elementos do sistema didático, como objetivos, métodos, posições teóricas, recursos, entre outros" (PAIS, 2001, p.66).

Assim, a figura do professor na construção do conhecimento desempenha a função de mediador e promotor da aprendizagem por meio de um processo de investigação, buscando fazer a articulação entre o conteúdo e a realidade dos estudantes de modo a tornar significativo o conhecimento. Quando tratamos do pólo estudante, voltamos o olhar para o estudante na condição de aprendente e de ser autônomo na construção do seu próprio saber em sentido dinâmico de forma que este seja coautor de sua aprendizagem, mediado pela figura do professor. Na perspectiva das práticas de sala de aula deveriam se pautar por ações estratégicas no sentido de desenvolvimento de uma atitude exploratória e investigativa que dêem oportunidades para interpretar 


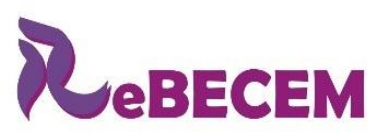

DOI: http://dx.doi.org/10.33238/ReBECEM.2019.v.3.n.2.22619

problemas, compreender enunciados das informações veiculadas pelos meios de comunicação.

Entendemos, portanto, que a Educação Estatística na EJA deve ser pensada como parte de um processo mais amplo de alfabetização e letramento, que se desenvolve ao longo de todo o Ensino Fundamental e Médio o que nos remete a importância de incorporar à Educação Estatística aos conhecimentos e procedimentos construídos e/ou adquiridos nas leituras que esses jovens e adultos realizam com as informações adquiridas através da mídia. Para tanto, é fundamental a abardagem sobre a educação estatística no que tange aos possiveis caminhos para que o aluno possa aprender de forma significativa e dinâmica a fim de que este possa alcançar um patamar de ser hermeneutico no sentido de refletir sobre seu próprio saber construido e sua formação enquanto cidadão o que nos induz a discorrer sobre alguns caminhos que viabilizem a aprendizagem no cerne da Educação Estatística, conforme é apresentado a sequir.

\title{
3 Educação estatística na educação de jovens e adultos
}

A inclusão da Educação Estatística no currículo escolar da EJA deve satisfazer o real papel significativo que envolve três componentes: utilidade, estudos posteriores e estética, com a seguinte justificativa:

\begin{abstract}
Utilidade. Todos os indivíduos precisam de alguns conhecimentos sobre estatística e probabilidades, para funcionarem na nossa sociedade (...). Estudos posteriores. Também para tratar situações com que se podem confrontar posteriormente, quer no campo da matemática, quer noutros campos científicos, os alunos precisam de ter conhecimentos na área da estatística e das probabilidades. Áreas científicas como a Biologia e as Ciências Sociais, que, ainda há pouco tempo, requeriam conhecimentos matemáticos mínimos, estão progressivamente a ficar dependentes de técnicas matemáticas sofisticadas, a maioria delas de natureza estatística (...). Estética. As considerações estéticas têm um papel importante na apreciação da beleza do assunto, quer na área da matemática, quer nas suas aplicações aos vários ramos da ciência, tecnologia e natureza. Esta atracção estética proporciona, quer uma apreciação do poder das técnicas, quer um conhecimento da responsabilidade da aplicação dessas técnicas (PEREIRAMENDOZA; SWIFT, 1989, p. 17).
\end{abstract}

Isto é, mesmo que a Estatística esteja presente na vida das pessoas o seu entendimento não é do domínio de todos (LAJOIE; JACOBS; LAVIGNE, 1995), o que torna necessário combater a literacia estatística a fim de que os cidadãos sejam estatisticamente letrado (GAL; GARFIELD, 1997; LAJOIE; JACOBS; LAVIGNE, 1995). Dessa modo, a literacia estatística, ou o letramento, estatístico está ligada (o) a 


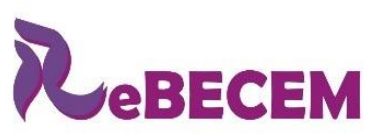

DOI: http://dx.doi.org/10.33238/ReBECEM.2019.v.3.n.2.22619

capacidade de interpretar, argumentar informações estatísticas em jornais, notícias e informações diversas (LAJOIE; JACOBS; LAVIGNE, 1995), isto é, de acordo com Pinto (2003, p. 113), "numa sociedade que já não é só de informação, mas, sobretudo de conhecimento, a literacia assume novas formas onde se jogam de forma definitiva processos variados de exclusão social”.

Corroborando com esta afirmativa, Garfield e Gal (1999, p. 211), aludem que o objetivo maior da Educação Estatística é "desenvolver as habilidades de raciocínio estatístico nos estudantes capacitando a produzir e a comunicar descrições, julgamentos, inferências e opiniões sobre informações de maneira significativa para eles”. Dessa maneira, o racicineo estatístico está atrelado à forma como as pessoas atribuem significado as informações estatísticas e o modo como elas raciocinam quando estão diante de uma informação, o que resultará em fazer uma interpretação e representação com base em um conjunto de dados na tomada de suas decisões.

Em consonância a isso, Ponte, Brocardo e Oliveira (2003, p.107), afirmam que a Educação Estatística "é um campo do estudo de problemas e situações reais, numa perspectiva de investigação contextualizada, que a Estatística e chamada a dar a sua grande contribuição para a Educação Matemática". Assim, quando esses autores aludem que o processo de ensino e aprendizagem de conceitos estatísticos precisam ser trabalhados com dados contextualizados e que tenham real significado para o estudante, os autores em questão, tratam, justamente, do fato para que esses alunos possam ser autônomos na realização de investigações, formulando questões, recolhendo, representando, organizando e interpretando dados, fazendo inferências e, a partir daí, colocando novas questões e reiniciando o ciclo investigativo (PONTE; BROCARDO; OLIVEIRA, 2003).

Nesse enfoque, Franklin et al., (2007, p. 6), argumentam que o papel da Educação Estatística é ajudar os estudantes a desenvolver o pensamento estatístico que a "grosso modo", é a habilidade de usar os saberes especificos da estatística e da probabilidade apreendidos e subjetivados que o aluno adquiri em interpretar de forma crítica e ética fenômenos que envolvem situações concretas referente ao acaso em sua vida , por meio da “[...] resolução dos problemas estatísticos e a tomada de decisões dependem da compreensão, interpretação e quantificação da variabilidade nos dados". Para esses autores, o pensamento estatístico consiste em ajudar o estudante a fazer suas escolhas pessoais, permitindo que seja capaz de manusear as idéias estatísticas e tomar suas decisões diante das informações, a esse respeito, Lopes (2008, p. 73) acredita que: 
DOI: http://dx.doi.org/10.33238/ReBECEM.2019.v.3.n.2.22619

A Educação Estatística não apenas auxilia na leitura e interpretação de dados, mas fornece a habilidade para que uma pessoa possa analisar/relacionar criticamente os dados apresentados, questionando/ponderando até mesmo sua veracidade. Para que se atinja essa etapa da criticidade não é suficiente oferecermos aos alunos apenas atividades de ensino que visem desenvolver a capacidade de organizar e representar uma coleção de dados, faz-se necessário interpretar e comparar esses dados para tirar conclusões.

De acordo com as assertivas acima, Mendonça e Lopes (2010, p. 159), ratificam que a "Educação Estatística deve proporcionar aos alunos ambientes de aprendizagem que lhes possibilitem construir competências para lidar com os conceitos estatísticos no seu cotidiano". Assim, o desenvolvimento de conteúdos relacionados a Educação Estatística deve priorizar um ambiente de aprendizagem por meio da problematização, permitindo com que os estudantes sejam autores do ciclo investigativo que perpassa pelo processo de coleta, organização e representação de dados, bem como sua interpretação e a iniciação as idéias da probabilidade (LOPES; CARVALHO, 2005).

Portanto, patirndo desse pressuposto, se faz necessário que o professor venha assumir em sala de aula uma postura crítica diante das informações vinculadas pelas mídias e buscar o desenvolvimento de atividades investigativas estatísticas que é perpassada pelas componentes e níveis descrito no quadro abaixo.

Quadro 1: Síntese dos componentes e níveis de atividades investigativas

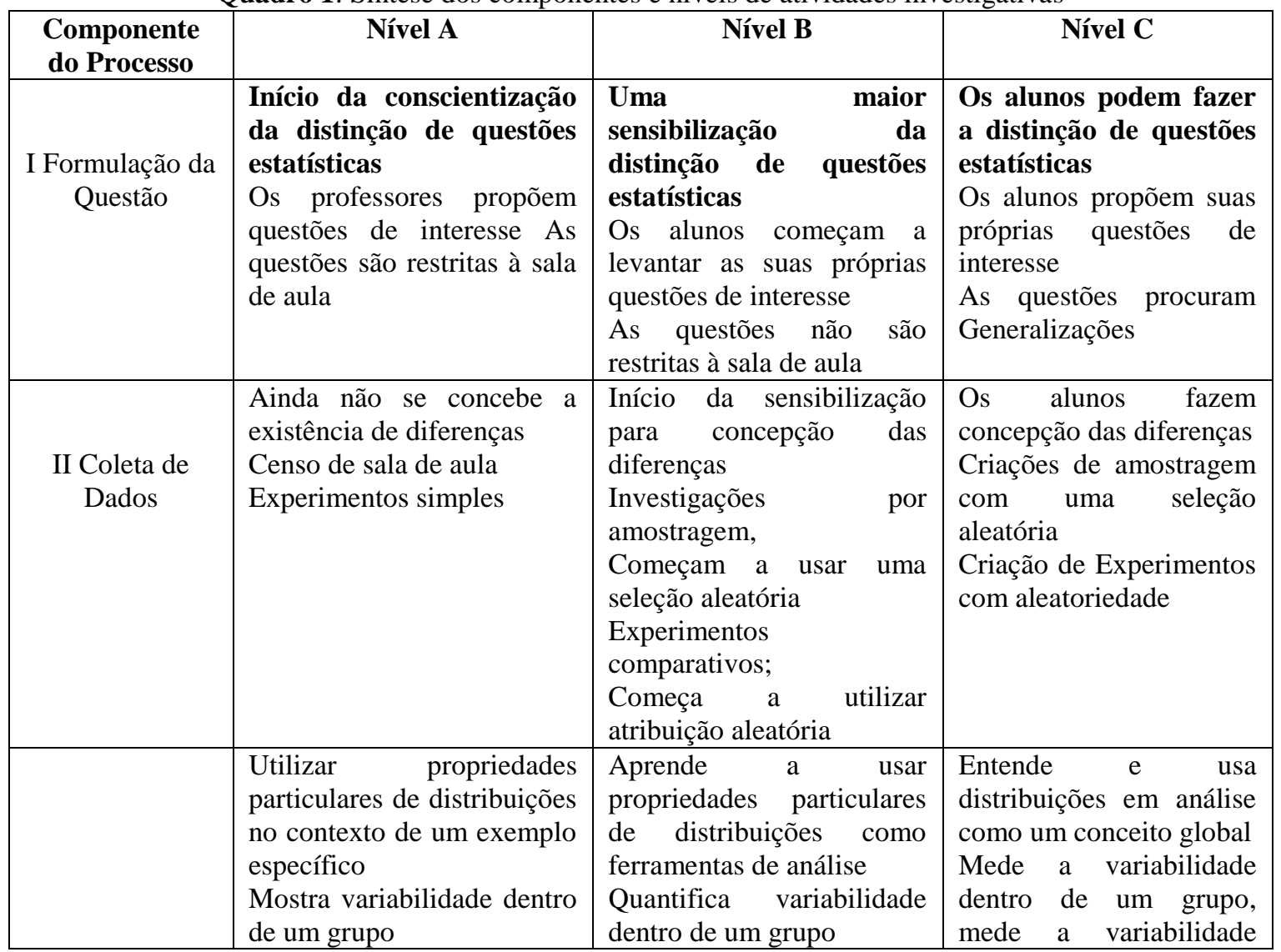


DOI: http://dx.doi.org/10.33238/ReBECEM.2019.v.3.n.2.22619

\begin{tabular}{|c|c|c|c|}
\hline $\begin{array}{c}\text { III Análises de } \\
\text { Dados }\end{array}$ & $\begin{array}{l}\text { Compara indivíduo para } \\
\text { indivíduo } \\
\text { Compara indivíduos com o } \\
\text { grupo } \\
\text { Início da consciência de } \\
\text { grupo para grupo } \\
\text { Observa associação entre } \\
\text { duas variáveis }\end{array}$ & $\begin{array}{l}\text { Compara grupo para grupo } \\
\text { em displays } \\
\text { Reconhece erro amostral } \\
\text { Algumas quantificações de } \\
\text { associação, modelos } \\
\text { simples de associação }\end{array}$ & $\begin{array}{l}\text { entre os grupos } \\
\text { Compara grupo para } \\
\text { grupo usando displays e } \\
\text { medidas de variabilidade } \\
\text { Descreve e quantifica } \\
\text { erro amostral } \\
\text { Quantificação } \\
\text { associação; montagem } \\
\text { dos modelos de } \\
\text { associação }\end{array}$ \\
\hline $\begin{array}{l}\text { IV Interpretação } \\
\text { dos Resultados }\end{array}$ & $\begin{array}{l}\text { Os alunos não olham para } \\
\text { além dos dados } \\
\text { Não generalização para } \\
\text { além da sala de aula } \\
\text { Nota diferença entre dois } \\
\text { indivíduos com diferentes } \\
\text { condições } \\
\text { Observa associação em } \\
\text { displays }\end{array}$ & $\begin{array}{l}\text { Os estudantes reconhecem } \\
\text { que, para além dos dados, } \\
\text { é viável } \\
\text { Reconhecem que uma } \\
\text { amostra pode ou não ser } \\
\text { representativa da } \\
\text { população maior } \\
\text { Observe a diferença entre } \\
\text { os dois grupos com } \\
\text { diferentes condições } \\
\text { É consciente da distinção } \\
\text { entre estudo observacional } \\
\text { e experimento } \\
\text { Nota diferenças na força de } \\
\text { associação } \\
\text { Básica interpretação de } \\
\text { modelos de associação } \\
\text { É consciente da distinção } \\
\text { entre associação de causa e } \\
\text { efeito }\end{array}$ & 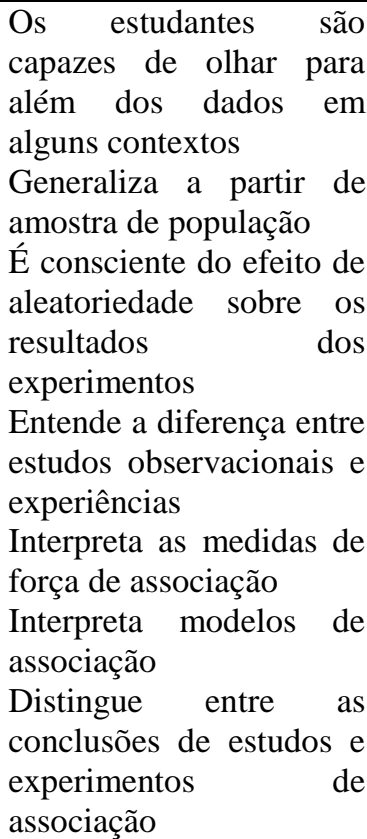 \\
\hline $\begin{array}{c}\text { Natureza da } \\
\text { Variabilidade }\end{array}$ & $\begin{array}{l}\text { Variabilidade de Medição } \\
\text { Variabilidade natural } \\
\text { Variabilidade Induzida }\end{array}$ & $\begin{array}{l}\text { Variabilidade } \\
\text { amostragem }\end{array}$ & Variabilidade ao acaso \\
\hline $\begin{array}{c}\text { Foco da } \\
\text { Variabilidade }\end{array}$ & $\begin{array}{l}\text { Variabilidade dentro de um } \\
\text { Grupo }\end{array}$ & $\begin{array}{l}\text { Variabilidade dentro de um } \\
\text { grupo e variabilidade entre } \\
\text { os Grupos } \\
\text { Covariabilidade }\end{array}$ & $\begin{array}{l}\text { Variabilidade no modelo } \\
\text { Apropriado }\end{array}$ \\
\hline
\end{tabular}

Fonte: Wild e Pfannkuch (1999)

De acordo com o quadro acima, o processo de ensino e aprendizagem voltado para o desenvolvimento de atividades investigativas estatísticas na sala de aula, deverá percorrer gradativamente os três componentes citados anteriormente, nessa pesquisa para que se tenha um estudante crítico frente as informações veiculadas pela mídia. Para tanto, buscamos, no item a seguir, tratar de interfaces existentes na educação estatística na EJA. Vejamos.

\section{Educação estatística na EJA: buscando interfaces}

No que tange as interfaces presentes na ducação Estatística na Educação de Jovens e Adultos é importante, acima de tudo, frisar que esta possui um campo de investigação que vem se consolidade no cenário Brasileiro o que nos impele a dar 


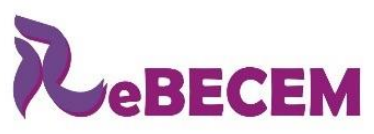

Revista Brasileira de Educação em

Ciências e Educação Matemática

ISSN 2594-9179

DOI: http://dx.doi.org/10.33238/ReBECEM.2019.v.3.n.2.22619

importância para a necessidade de uma ampla discussão sobre as possibilidades de busca por estudos e pesquisa que fundamentam as aplicações e implicações em sala de aula do ensino e aprendizagem da Estatística, Combinatória e Probabilidade. Assim, a Educação Estatística na Educação de Jovens e Adultos representa um instrumento norteador para o desenvolvimento de um estudante crítico e competências para que possa lidar com os conceitos estatísticos no seu cotidiano. Dessa forma, estudantes que apenas não sejam só "estatísticos aficionados", mas capazes de ter habilidades em compreender, interpretar, avaliar, criticar e tirar decisões com base em informações estatísticas (BATANERO, 2002).

Batanero (2001, p. 118-119), a esse respeito, argumenta que a utilização de exemplos que estimulem a argumentação e interpretação de dados são fundmanetais para o aprendizado do aluno, pois se quisermos "que o aluno valorize o papel" das "probabilidades e estatística, é importante que os exemplos que mostramos na sala de aula sejam da forma mais ampla possível (...) [e incluam aplicações] do seu mundo biológico, físico, social e político".

Entretanto, se torna necessária uma formação continuada para professores que desenvolvem suas atividades na sala de aula da EJA, para que este possa vir a exercer o seu papel como mediador na construção e/ou aprimoramento do conhecimento do estudante. Em corroboração com essas assertivas, inferimos que é importante que haja uma maior formação que permita que os professores se apropriem dos conteúdos relacionados à Educação Estatística para lhe conferir um melhor encaminhamento no processo ensino e aprendizagem, possibilitando-os fazer com que os estudantes se apropriem dos conhecimentos desejados.

Nesse viés, Batanero (2002), ao destacar sobre a relevância da formação do professor e da motivação em desenvolver nas suas aulas de matemáticas aspectos relativos ao ensino e aprendizagem de conceitos Estatísticos e, consequentemente, criarem o desenvolvimento de uma cultura estatística em sala de aula, destaca que o professor precisa desenvolver em sala um ambiente de aprendizagem que esteja a todo o momento mediada pela comunicação e que o diálogo faça parte do "desenvolvimento do pensamento científico, levando o aluno a intuir, conjecturar, experimentar, provar, avaliar e ainda para o reforço das atitudes de autonomia e cooperação" (ALVES; BARBEDO; FONSECA, 1992, p. 285).

Assim, é cruscial que o professor ao desenvolver suas atividades em sala de aula possibilite aos estudantes, em geral, a oportunidades de aprender, pensar e se posicionar 


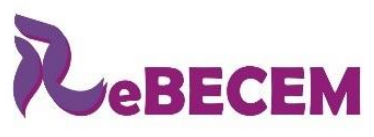

DOI: http://dx.doi.org/10.33238/ReBECEM.2019.v.3.n.2.22619

criticamenteperante aos problemas do dia-dia, buscando e discutindo soluções, tomando decisões e construindo a sua cidadania diante das mais variadas informações veiculadas pelas mídias (GONÇALVES, 2000). No entanto, este precisa preparar o estudante a lidar com os mais variados problemas que possam emergir, futuramente, em sua vida, criando situações que possibilitem discussões e reflexões na busca por soluções proficuos, ou seja, mais proveitoso ou proeficiente. Tal como é defendido por Téran (1998), Lopes (2000, p. 171), ao ratificarem que:

O professor precisará, além de atualizar e construir seus próprios conhecimentos sobre o tema, refletir sobre o quanto ele se opõe ao determinismo, ao mesmo tempo em que poderá visualizar o fato de que vivemos num mundo que é simultaneamente estocástico e determinista.

Sobre o exposto, se nota que alguns autores têm voltados seus estudos para o ensino e aprendizagem da Estatística (BATANERO, 2002; CARVALHO, 2001), em que sugerem que o conteúdo possa desenvolver a autonomia, capacidade de criticidade, comunicação e as habilidades em trabalhar com dados, se possíveis relacionados com as suas vivências e interesses, isto é, que estejam próximos das experiências e necessidades dos estudantes. Olhando pelo prisma metodológico do desenvolvimento de atividades em sala de aula de conceitos estatísticos, se pode partir por meio dos interesses reais dos estudantes para coletar e organizar os conjuntos de dados, buscando envolver a realidade dos estudantes em contextos de exploração de informações significativos e, além disso, se buscar trabalhar com temas que busquem promover a oportunidades de atividades interdisciplinaridade, como forma de interligar a Estatística a outras áreas do conhecimento.

Para que isso ocorra, é importante que o campo metodológico que o desenvolvimento da Educação Estatística na sala de aula da EJA seja consolidado por meio do cenário de investigação, pois este sem duvida possbilitará um trabalho investigativo mais eficiente, além de apresentar diferentes ambientes de aprendizagem, em que o estudante venha se tornar protagonista durante todo o processo do desenvolvimento de uma determinada atividade (SKOVSMOSE, 2000). Além disso, os atores desse ambiente de aprendizagem (estudante e o professor) assumem responsabilidades e obrigações pelo desenvolvimento do conhecimento matemático escolar, por meio de situações-problemas, preferencialmente, ligada a sua realidade (CHAVES, 2000).

Logo, é fundamental que durante o trabalho de investigação estatística o levantamento e a formulação do problema deva ser respondido pelo próprio estudante, 


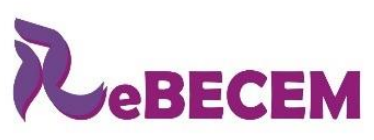

DOI: http://dx.doi.org/10.33238/ReBECEM.2019.v.3.n.2.22619

mediado pelo professor, o que garantirá uma aprendizagem significativa apresentando um nível elevado de envolvimento, pois o estudante é incluido como um todo na experiência a partir da qual aprende (GAZZETTA, 1989). Com relação a isso, Oliveira e Lopes (2013, p. 915), afirmam que o trabalho com a Educação Estatística propiciam os alunos a "compreender muitas das características da complexa sociedade atual, ao mesmo tempo que facilita a tomada de decisões em um cotidiano em que a variabilidade e a incerteza estão sempre presentes”.

Nesse foco, tanto os estudos de Scheeffer (2000), como as pesquisas de Cobb (1999), destacam a relevância da compreensão que a maioria dos alunos em geral tem da coleta, da organização e da interpretação de dados quando estão envolvidos em um determinado ambiente investigativo para que estes possam desenvolver sua criticidade e manusear significativamente os procedimentos ligados aos próprios conceitos estatísticos.

Vale destacar, que a Educação Estatística na EJA pode ser interpretada como um Cenário para Investigação, segundo a perspectiva desses autores, os (as) estudantes são aprendentes construtor a desenvolverem um trabalho, cujo tema é escolhido por eles e o professor age como mediador de todo o processo de ambiente de aprendizagem, pois "é necessário estarmos aptos a saber ler e interpretar, assim como a utilizar convenientemente essa forma de transmitir a informação" (MARTINS; CERVEIRA, 1999, p. 9).

No entender de Carvalho (2001, p. 473),

O contexto de realização das tarefas, as instruções de trabalho, a natureza das tarefas, o estatuto de quem as apresenta e de quem as resolve, os contratos didácticos ou experimentais existentes, os meta-contratos que os regem, são elementos fundamentais para compreender e interpretar uma realidade que se afigura complexa e dinâmica.

Em conformidade com o asseverado acima, a Educação Estatística na EJA pode ser adequada as Tecnologias de Informação e Comunicação (TIC) por proporcionar um ambiente interativo e dinâmico na prática de sala de aula por meio de softwares, como por exemplo o softwares Bio Estat, o Mini tab e o StatDisc, dentre outros, na aprendizagem de forma a contribuir de forma significativa para o processo de ensino e aprendizagem, pois as TIC permitem ao estudante que a exploração seja realizada de uma maneira mais dinâmica, deixando de ser apenas meros expectadores, passando para a posição de agente primordial de sua aprendizagem, buscando desenvolver suas competências, habilidades, criticidade e autonomia diante de realidade que o cerca. 
DOI: http://dx.doi.org/10.33238/ReBECEM.2019.v.3.n.2.22619

Ainda sobre a importancia do uso das TIC na EE, Dias e Junior (2018, p. 230232) ressaltam que:

\begin{abstract}
no processo educativo nas escolas brasileiras ainda abarca muitos desafios, que vão desde a elaboração e execução de projetos e políticas públicas que garantam um mínimo de infraestrutura às instituições, até a formação crítica do docente para a escolha, a avaliação e o uso coerente das tecnologias.[...].Nas escolas brasileiras ainda abarca muitos desafios, que vão desde a elaboração e execução de projetos e políticas públicas que garantam um mínimo de infraestrutura às instituições, até a formação crítica do docente para a escolha, a avaliação e o uso coerente das tecnologias.
\end{abstract}

Ou seja, para Corrêa (2013, p. 264), uma ferramenta de fundamental importância na EE é o computador "na medida em que se apresenta de forma multissensorial, integrada, intuitiva e interativa. Tal tecnologia apresenta informações que atendem, de forma direta ou indireta, aos diversos enfoques" inerentes ao processo de ensino e aprendizagem.

Além disso, o trabalho com projetos como recurso para a introdução de conceitos estatísticos pode auxiliar o professor a promover um ambiente de aprendizagem em que o aluno escolhe o contexto em que irá trabalhar no intuito de desenvolver seus estudos e aprender novos conceitos de modo prático, promovendo uma aprendizagem mais sólida e interessante.

Nessa ótica, a utilização de softwares na aprendizagem dos conceitos e habilidades relacionadas a Estatísticos estimula o estudante a elaborar, experimentar e avaliar as informações ao longo da investigação e exploração estatística, a fim de aprimorar e desenvolver seus conhecimentos e ampliar da visão que os estudantes possuem sobre a Estatística (DIAS; JUNIOR, 2018).

Isto é, a aprendizagem de conceitos Estatísticos por meio de softwares pode possibilitar a expansão e a (re)construção de novos conhecimentos e a melhoria do desempenho, ultrapassando a mera memorização acumulativas de fórmulas e tornando o ambiente de aprendizagem mais significativa para o estudante e o professor.

\title{
5 Considerações finais
}

No decorrer deste ensaio teórico em considerar distintas perspectivas de Educação Estatística na Educação de Jovens e Adultos e da possibilidade do confrontálas para a prática em sala de aula podemos observar indicios de contribuições da Educação Estatística na EJA para despertar o interesse dos professores e estudantes pela aprendizagem da Estatística e para o desenvolvimento de suas competências gerais. 


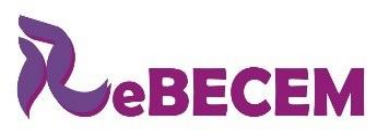

Revista Brasileira de Educação em

Ciências e Educação Matemática

ISSN 2594-9179

DOI: http://dx.doi.org/10.33238/ReBECEM.2019.v.3.n.2.22619

Buscamos apontar a necessidade de se trabalhar os conteúdos de Estatística, Probabilidade e Combinatória na perspectiva da Educação Estatística, quando a problematização tem papel central no processo de ensino e de aprendizagem na sala de aula da EJA.

Assim, a Educação Estatística (EE), se apresenta como mais uma área de investigação que estuda problemas relacionados ao ensino e de aprendizagem de conceitos estatísticos, combinatórios e probabilísticos em sala de aula. Em que seus fundamentos repousam em problemas significativos para os estudantes, de forma a envolvê-los em uma investigação estatística, articulando Combinatória e Probabilidade. A partir dessa visão, o ensinar desses conceitos torna-se sinônimo de ensinar a resolução de problemas (LOPES, 2008). Dessa forma, além de desenvolver conteúdos específicos de Estatística, Combinatória e Probabilidade, a Educação Estatística é igualmente relevante "por se ter tornado no aspecto primordial da reavaliação geral da natureza e função dos programas de educação matemática” (MEIRINHOS, 1999, p. 21 22).

Logo, a Educação Estatística na EJA pode contribuir para a formação de um cidadão estatisticamente crítico e reflexivo, com habilidades de avaliar as informações estatísticas presentes no seu dia-a-dia. Assim, o processo de ensino e aprendizagem Educação Estatística na EJA que envolve o processo de Investigação Estatística, possibilita ao estudante o aprimoramento de suas competências e habilidades que lhe possibilitarão o exercício da cidadania, por meio da capacidade de analisar criticamente informações e assim definir suas próprias estratégias para solucionar situações problema.

A inclusão da Educação Estatística na EJA possibilita a esses estudantes a real necessidade de apreciar o uso da estatística no seu dia-a-dia; o papel desempenhado pelo raciocínio estatístico em outras disciplinas do currículo, na utilização e na interpretação de gráficos e na familiarização com os computadores e calculadoras (BARNETT, 1982; HOLMES, 1980). Ao nosso ver, essa inclusão possibilita aos alunos aprender como interpretar resultados de uma investigação estatística e colocar questões críticas e reflexivas sobre argumentações que se referem aos dados ou sínteses estatísticas (LOPES, 2008).

Portanto, a Educação Estatística na EJA é campo de investigação propício para informação teórica e empírica sobre a aprendizagem e as dificuldades de compreensão desse campo de investigação. Espera-se que essa reflexão contribua para a 


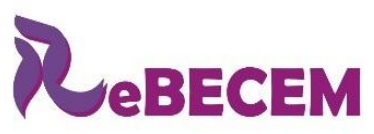

DOI: http://dx.doi.org/10.33238/ReBECEM.2019.v.3.n.2.22619

implementação cada vez mais de conteúdos de Estatísticas, combinatórios e Probabilísticos possam fazer parte da prática pedagógica de professores que ensinam matemática na EJA. Um possível indicativo para o desenvolvimento da EE na sala de aula da EJA seria dar ênfase a necessidade de leitura e interpretação de gráficos e tabelas com dados reais que fazem parte da realidade cotidiana dos alunos, tais como: formulação de questões, levantamento de hipóteses, escolha das variáveis, representatividade de uma amostra, apresentação, discussão e verificação dos resultados encontrados. No entanto, observamos que uma das dificuldados da inserção efetiva da Educação Estatística na EJA se refere à falta de materiais didáticos/pedagógicos validados e adequados à realidade das escolas que atendem a esta modalidade de ensino (CAZORLA; GUSMÃO; KATAOKA, 2011; WALICHINSKI; SANTOS JUNIOR; ISHIKAWA, 2014).

Outra questão observada é a necessidade de orferecimento de cursos de formação inicial e continuada para professores que ensinam Matemática na Educação Básica, o que pode contrubuir para que a Educação Estatística seja trabalhada de forma gradativa nas aulas de Matemática. Nessa mesma perspectiva, Lopes (2010, p. 48) afirma que os conteúdos de Estatística e Probabilidade “[...] ainda não têm sido prioridade na escola, nem nos programas de formação inicial e contínua de professores que ensinam Matemática". Corroborando com essa ideia, Borba et al., (2011), argumentam que a efetivação da Educação Estatística na Educação Básica é ainda incipiente, se comparada à Álgebra, à Geometria e à Aritmética.

E por fim, a necessidade de uma articulação entre esses conteúdos de Estatística, Probabilidade e Combinatória para a realização de um trabalho mais significativo com esses conteúdos desde a Educação Infantil (WALICHINSKI; SANTOS JUNIOR; ISHIKAWA, 2014). Destacamos a relevância da introdução do processo de modelagem matemática, as atividades investigativas e a inserção de tecnologias como essenciais ao processo de ensino e aprendizagem da Educação Estatística (LOPES, 2013). Caminhando para uma possível (re) organização curricular para tratar especificamente dos objetivos da Educação Estatística. Destacamos também a necessidade de elaboração e validação de materiais didáticos/pedagógicos acessíveis ao professor que ensina Matemática para que este venha a subsidiar sua prática pedagógica a fim de contribuir para a efetivação da Educação Estatística nas escolas (WALICHINSKI; SANTOS JUNIOR, 2013). 


\section{Referências}

DOI: http://dx.doi.org/10.33238/ReBECEM.2019.v.3.n.2.22619

ALVES, C. B., BARBEDO, J. E FONSECA, M. G. Probabilidades e Estatística. In: COMISSÃO ORGANIZADORA PROFMAT 92. (ed.). ProfMat 92. Viseu: Associação de Professores de Matemática, 1992. p. 285-293.

ARROYO, M. Uma escola para jovens e adultos. In: REFLEXÃO SOBRE A EDUCAÇÃO DE JOVENS E ADULTOS NA PERSPECTIVA DA PROPOSTA DE REORGANIZAÇÃO E REORIENTAÇÃO CURRICULAR, 2003, São Paulo. Anais... São Paulo: [s.n.], 2003.

ARROYO, M. G. Educação de jovens e adultos: um campo de direitos e de responsabilidade pública. In: SOARES, L.; GIOVANETTI, M. A.; GOMES, N. L. (org.). Diálogos na educação de jovens e adultos. Belo Horizonte: Autêntica, 2005. p. 19-50.

BARNETT, V. Teaching statistics in schools Throughout the world. Voorburg: International Statistical Institute, 1982.

BATANERO, C. Didáctica de la Estadística. Granada: Universidade de Granada, 2001. Disponível em: http://www.ugr.es/local/batanero. Acesso em: 17 nov. 2012.

BATANERO, C. Los retos de la cultura estadística. In: JORNADAS INTERAMERICANAS DE ENSEÑANZA DE LA ESTADÍSTICA, 2002, Buenos Aires. Anais... Buenos Aires: [s.n.], 2002.

BIANCHINI. F.; NEHRING, C. M. As pesquisas sobre o Ensino de Estatística: um estudo a partir da produção acadêmica. In: ESCOLA DE INVERNO DE EDUCAÇÃO MATEMÁTICA, 3., 2012, Santa Maria. Anais... Santa Maria: [s.n.], 2012. p. 1-10.

BORBA, R. et al. Educação Estatística no Ensino Básico: Currículo, pesquisa e prática em sala de aula. EM TEIA: Revista de Educação Matemática e Tecnológica Iberoamericana, Recife, v. 2, n. 2, p. 1-18, 2011.

BRASIL. Ministério da Educação. Parâmetros Curriculares Nacionais (PCN): matemática. Brasília, DF, 1997.

BRASIL, Secretaria de Educação Fundamental. Ministério da Educação. Secretaria deEducação Fundamental. Proposta Curricular para a Educação de Jovens e Adultos: Segundo Segmento do Ensino Fundamental: $5^{\mathrm{a}}$ a $8^{\mathrm{a}}$ série. Brasília, 2002. Disponível em: http://portal.mec.gov.br/secad/arquivos/pdf/eja/propostacurricular/segundosegmento/vol3_mate matica.pdf. Acesso em: 23out. 2018.

CAMPOS, C. R. et al. Educação Estatística: teoria e prática em ambientes de modelagem matemática. Belo Horizonte: Autêntica Editora, 2011.

CARRAHER, T.; CARRAHER, D. Na vida dez, na escola zero. Os contextos culturais de aprendizagem da matemática. 14. ed. São Paulo, Cortez, 2006.

CARVALHO, C. Interação entre pares. Contributos para a promoção do desenvolvimento lógico e do desempenho estatístico no . $^{\circ}$ ano de escolaridade. Tese de doutoramento não publicada, Universidade de Lisboa, Lisboa, 2001.

CAZORLA, I. M.; GUSMÃO, T. C. R. S.; KATAOKA, V. Y. Validação de uma sequência didática de probabilidade a partir da análise da prática de professores, sob a ótica do enfoque ontosemiótico. Bolema, Rio Claro, v. 24, n. 39, p. 537, 2011. 
DOI: http://dx.doi.org/10.33238/ReBECEM.2019.v.3.n.2.22619

CAZORLA, I. M.; KATAOKA, V. Y.; SILVA, C. B. Trajetória e Perspectivas da Educação Estatística no Brasil: um olhar a partir do GT12. In: LOPES, C. E.; COUTINHO, C. Q. S.; ALMOULOUD, S. A. (org). Estudos e Reflexões em Educação Estatística. 1. ed. Campinas: Mercado das Letras, 2010. p. 19-44.

CHAVES, S. N. A construção coletiva de uma prática de formação deprofessores de ciências: tensões entre o pensar e o agir. 2000. Tese (Doutorado em Educação) - Faculdade de Educação, Universidade Estadual de Campinas, Campinas, 2000.

COBB, P. Individual and collective mathematical development: The case of statistical data analysis. Mathematical Thinkingand Learning, Lodres, v. 1, n. 1, p. 5-43, 1999.

CORRÊA, A. de A. Saberes docentes e o ensino da estatística: considerações sobre a ação pedagógica. Revista Espaço Pedagógico, Passo Fundo, v. 20, n. 2, p. 351-367, jul./dez. 2013.

D’AMBRÓSIO, U. Etnomatemática: elo entre as tradições e a modernidade. 2. ed. Belo Horizonte: Autêntica, 2002.

DIAS, C. F. B.; SILVA, G. C.; JUNIOR, G. S. J. A Educação Estatística nos anos iniciais do Ensino Fundamental no Brasil: uma análise curricular. Revista Thema, Pelotas, v. 14, n. 2, p. 122-136, 2017.

DIAS, C. F. B.; JUNIOR, G. S. Ensino de Probabilidade e Estatística e Tecnologias da Informação e Comunicação: um cenário das produções brasileiras para os anos iniciais do Ensino Fundamental. Abakos, Belo Horizonte, v. 7, n. 1, p. 3-23, nov. 2018.

FANTINATO, M. C. C. B. Contribuições da etnomatemática na educação de jovens e adultos: algumas reflexões iniciais. In: RIBEIRO, J. P. M.; DOMITE, M. C. S.; FERREIRA, R. (org). Etnomatemática: papel, valor e significado. 2. ed. Porto Alegre: Zouk, 2006. p. 01-10.

FONSECA, M. C. F. R. Educação Matemática de Jovens e Adultos. 2. ed. Belo Horizonte: Autêntica, 2002.

FONSECA, M. C. F. R. Educação matemática de jovens e adultos: especificidades, desafios e contribuições. 2. ed. Belo Horizonte: Autêntica, 2005.

FRANKLIN, C. et al. Guidelines for Assessment and Instruction in Statistics Education (GAISE) Report: a pre-K-12 curriculum framework. Alexandria/VA: ASA, 2007.

GAL, I.; GARFIELD, J. Curricular goals and assessment challenges in statistics and education. In: GAL, I.; GARFIELD, J. (ed.). The Assessment Challenges in Statistical Educational. 1. ed. Voorburg: International Statistical Institute, 1997. p. 1-13.

GARFIELD, J. B.; GAL, I. Teaching and Assessing Statistical Reasoning. In: STIFF, L.; CURCIO. F. Developing Mathematical Reasoning in Grades K-12. USA: The National Council of Teachers of Mathematics. 1. ed. Reston-VA: Editora, 1999. p. 207-219.

GAZZETTA, M. A modelagem como estratégia de aprendizagem da matemática em cursos de aperfeiçoamento de professores. 1989. Dissertação (Mestrado em Educação Matemática) Instituto de Geociências e Ciências Exatas, Universidade Estadual Paulista, Rio Claro, SP, 1989.

GONÇALVES, T. O. A formação e desenvolvimento profissional de formadores de professores: O caso dos professores de matemática da UFPa. 2000. Tese (Doutorado em Educação) - Faculdade de Educação, Universidade Estadual de Campinas, Campinas, 2000. 
DOI: http://dx.doi.org/10.33238/ReBECEM.2019.v.3.n.2.22619

GUIMARÃES, G. et al. A Educação Estatística na educação infantil e nos anos iniciais.

Zetetiké, Campinas, v. 17, n. 32, p. 11-28, jul./dez. 2009.

HOLMES, P. Teaching Statistics 11-16. 1. ed. Slough: Foulsham Educational, 1980.

LAJOIE, S. P.; JACOBS, V. R.; LAVIGNE, N. C. Empowering children in the use of statistics. Journal of Mathematical Behavior, EUA, v. 14, n. 4, p. 401-425, 1995.

LOPES, C. A. E. A Probabilidade e a Estatística nas salas de aula da Educação Infantil. In: ACTAS DO PROFMAT, 2000, Ilha da Madeira. Anais... Portugal: [s.n.], 2000. p. 166-174.

LOPES, C. O ensino da estatística e da probabilidade na educação básica e a formação dos professores. Cad. Cedes, Campinas, v. 28, n. 74, p. 57-73, jan./abr. 2008.

LOPES, C. Os desafios para Educação Estatística no Currículo de Matemática. In: LOPES, C. E. Estudos e reflexões em Educação Estatística. 1. ed. Campinas: Mercado das Letras, 2010. p. 47-64.

LOPES, C. Educação Estatística no Curso de Licenciatura em Matemática. Bolema, Rio Claro, v. 27, n. 47, p. 901-915, 2013.

LOPES, C. E.; CARVALHO, C. Literacia Estatística na Educação Básica. In: NACARATO, A.; LOPES, C. A. E. Leituras e Escritas na Educação Matemática. 1. ed. Belo Horizonte: Autêntica, 2005. p.77-92.

MENDONÇA, L.; LOPES, C. E. O Trabalho com Educação Estatística no Ensino Médio em um Ambiente de Modelagem Matemática. In: LOPES, C. E.; COUTINHO, C. Q. S.;

ALMOULOUD, S. Estudos e reflexões em Educação Estatística. 1. ed. Campinas: Mercado das Letras, 2010.

MAGALHÃES, M. Desafios do ensino de Estatística na licenciatura em Matemática. In: SAMÁ, S.; PORCIÚNCULA, M. (org). Educação Estatística: Ações e estratégias pedagógicas no Ensino Básico e Superior. 1. ed. Curitiba: CRV, 2015. p. 41-54.

MARTINS, M. E. G.; CERVEIRA, A. G. Introdução às Probabilidades e à Estatística. 1. ed. Lisboa: Universidade Aberta, 1999.

MEIRINHOS, A. L. V. F. A importância da Estatística e das Probabilidades no ensino. Dissertação de Mestrado não publicada, Departamento de Estatística e Investigação Operacional da Faculdade de Ciências da Universidade de Lisboa, Lisboa, 1999.

OLIVEIRA, D.; LOPES, C. A. E. A prática docente em estocástica, revelada por professoras que ensinam matemática nos anos iniciais do ensino fundamental Educação Matemática Pesquisa. Revista do Programa de Estudos Pós-Graduados em Educação Matemática, [S.I.], v. 15, n. 4, p. 909-925, 2013.

PAIS, L. C. Didática da Matemática: uma análise da influência francesa. 2. ed. Belo Horizonte: Autêntica, 2001.

PEREIRA-MENDOZA, L.; SWIFT, J. Porquê ensinar estatística e probabilidades. Educação e Matemática, Lisboa, v. 9, n. 36, p. 17-18, 1989.

PINTO, M. C. A. O ensino da Matemática: Situações e perspectivas. Lisboa: Ministério da Educação e Ministério da Ciência e do Ensino Superior, 2003, p. 113-115. 
DOI: http://dx.doi.org/10.33238/ReBECEM.2019.v.3.n.2.22619

PONTE, J. P.; BROCARDO, J.; OLIVEIRA, H. Investigações Matemáticas na sala de aula. 1. ed.. Belo Horizonte: Autentica, 2003.

SEVERINO, A. J. Metodologia do trabalho científico. 20. ed. São Paulo: Cortez, 1996.

SEVERINO, A. J. Metodologia do trabalho científico. 23. ed. São Paulo: Cortez, 2007.

SCHEFFFER, R. Statistics for a new century. In: BURKE, M.; CURCIO, F. (ed.). Learning Mathematics for The New Century. Reston: NCTM, 2000. p. 158-173.

SILVA, J. F.; CURI, E.; SCHIMIGUEL, J. Um Cenário sobre a Pesquisa em Educação Estatística no Boletim de Educação Matemática- BOLEMA, de 2006 até 2015. Bolema, Rio Claro, v. 31, n. 58, p. 679-698, ago. 2017.

SKOVISMOSE, O. Cenários de Investigação. Bolema, Rio Claro, n. 14, p. 66 - 91, 2000.

TERÁN, T. E. Are we preparing teachers and pupils in statistics for the nextcentury? In: PEREIRA-MENDOZA, L. (ed.). Proceedings of the Fifth International Conference on Teaching of Statistics.Vooburg: International Statistical. 2. ed. Singapura: CTMA Ltd, 1998. p. 18-23. Disponível em: http://www.stat.auckland.ac.nz/ iase/publications. Acesso em: 17 nov. 2012.

WALICHINSKI, D.; SANTOS JUNIOR, G. Educação estatística: objetivos, perspectivas e dificuldades. Imagens da Educação, Marigá, v. 3, n. 3, p. 31-37, 2013.

WALICHINSKI, D.; SANTOS JUNIOR, G.; ILHIKAWA, E. C. M. Educação estatística e parâmetros curriculares nacionais: algumas considerações. R. B. E. C. T., Curitiba-PR, v. 7, n. 3, p. 44-62, set./dez. 2014.

WILD, C.; PFANNKUCH, M. Statistical thinking in empirical enquiry. International Statistical Review, [S.I.], n.67, p. 223-65, 1999.

Recebido em: 15 de junho de 2019.

Aceito em: 13 de agosto de 2019. 